\title{
Modeling individual growth trajectories of the female European eel in relation to temperature and habitat-use history in the Gironde River, France
}

\author{
Kazuki Yokouchi ${ }^{1,2,3, *}$, Françoise Daverat ${ }^{1}$ \\ ${ }^{1}$ IRSTEA, Unité EPBX, 50 avenue de Verdun, 33612 Cestas cedex, France \\ ${ }^{2}$ Atmosphere and Ocean Research Institute, The University of Tokyo, 5-1-5, Kashiwanoha, Kashiwa 277-8564, Japan \\ ${ }^{3}$ Present address: Institute for East China Sea Research, Nagasaki University, 1551-7, Tairamachi, Nagasaki 851-2213, Japan
}

\begin{abstract}
Although the average growth rate of European eel is known to be generally dependent on temperature and habitat at the population scale, large variation in growth among eels in a single river basin can also be widely observed. In this study, individual growth trajectories of female European eels in the Gironde River basin, France, were modeled with habitat-use histories and thermal variations in relation to regional climatic events such as the heat wave in 2003 observed in SW Europe. A mixed-effects model was used to take into account the repeated measures of individual growth of 173 female eels in 1993 to 2003, obtained from otolith structure and chemistry. Temperature effect was tested using a proxy of efficient temperature for growth between 2 thermal thresholds in a year. The models with thresholds for growth between 12 and $15^{\circ} \mathrm{C}$ (lower) and $18^{\circ} \mathrm{C}$ (higher) were selected considering Akaike's information criterion. Individual annual growth estimates were higher in the estuary habitat than in the river habitat. Estimated growth was higher when eels shifted habitats between freshwater and brackish water or seawater. The years 1999 and 2001 had, respectively, the lowest and highest temperature proxy value, showing that a longer growing season (moderate summer/warm winter) had a positive effect on growth. The 2003 heat wave had a negative effect on eel growth, reflected by the lower temperature proxy value. The same approach could be used in the future to estimate the effect of global climate change on the growth and distribution of eels at local and regional scales.
\end{abstract}

KEY WORDS: Anguilla anguilla - Inter-annual temperature variation - Habitat-use history · Mixed-effects model

\section{INTRODUCTION}

Temperature is a primary driver of all aspects of the physiology of ectotherms, including growth dynamics. Evaluation of the direct and indirect impacts of climate change on the growth dynamics of fish is an important issue, because mean annual temperature has already increased by $2^{\circ} \mathrm{C}$ in the past century and the projections of European climate predict an increase of 1.4 to $5.8^{\circ} \mathrm{C}$ within the next $50 \mathrm{yr}$ (IPCC 2001). Furthermore, European climate is predicted to oscillate more frequently between normal and extreme climatic conditions. Extreme climatic events, such as the 2003 heat wave that was observed in western Europe, may cause disruption in the life histories of organisms (Jolly et al. 2005).

The European eel Anguilla anguilla has a large temperate distribution, from northern Africa to northern Europe during its growth phase (Tesch 2003). This migratory fish spawns in the Sargasso Sea and undertakes 2 transoceanic migrations across the Atlantic Ocean during its larval phase and pre- 
reproductive stage. The European eel forms a unique population from a genetic perspective (reviewed by Tesch 2003, Aoyama 2009), making the eel a model of choice to study the effects of environment on lifehistory traits. Thus, one can expect that eel growth traits respond to drivers such as temperature and habitat productivity, which can be partly determined by the passive transport of larvae from the spawning ground to the continental growth habitat. The growth phase of eels is very plastic, as eels may occupy many different environments along a large latitudinal gradient (Daverat et al. 2012).

Anguillid eels have several habitat-use patterns as shown by otolith microchemistry. While some eels spend their whole growth phase in freshwater, others remain in brackish or seawater (Tsukamoto et al. 1998). In addition, some eels change habitats during their growth phase (e.g. Tsukamoto et al. 1998, Tsukamoto \& Arai 2001, Jessop et al. 2004, 2008, Daverat \& Tomas 2006, Kaifu et al. 2010, Yokouchi et al. 2012). Studies on growth of anguillid eels showed that eels living in brackish habitats had a higher growth rate than eels living in freshwater habitats (e.g. Helfman et al. 1987, Morrison \& Secor 2003, Melia et al. 2006, Yokouchi et al. 2008, Cairns et al. 2009). Models of eel growth at the population level confirmed that growth was also dependent on the age of the fish and habitat characteristics (Daverat et al. 2012).

A latitudinal cline in the growth rate of eels was observed in the continental habitats of temperate eels (Vøllestad 1992, Jessop 2010, Daverat et al. 2012). This latitudinal cline was at least partly explained by a temperature effect. The effect of temperature on eel growth was established from experiments. It was demonstrated that an optimal rearing temperature for the eel is 23 to $25^{\circ} \mathrm{C}$, and eel growth in culture ceased under a temperature of $12^{\circ} \mathrm{C}$ (Sadler 1979, Dosoretz \& Degani 1987, Holmgren 1996, Ciccotti \& Fontenelle 2001).

Individual growth models are particularly suited to distinguish between individual growth variation and the influence of environment factors. Annual increments in otoliths were found to respond to climate effects (Black 2009) in the same way as sea shells and trees do, making otolith annual increments a tool of choice to study the impact of climate on fish growth traits. Otoliths can be used to estimate the growth chronology of a fish by estimating the size-at-age, inferred by back-calculation methods (Francis 1990). These techniques have also been applied to estimate the growth patterns of eels (e.g. Tzeng et al. 2000, Oliveira \& McCleave 2002, Jessop et al. 2004, Dav- erat \& Tomas 2006, Lamson et al. 2009). However, classic back-calculation methods do not take into account the fact that annual increments are repeated measures of size of an individual fish. Recently, mixed-effects models were developed for the estimation of fish growth (Weisberg et al. 2010), to overcome the lack of independence among the data from the same individual to classic models by considering the random effect of individuals in addition to the fixed effects of the objective model parameters.

The aim of the present study was to investigate the effect of temperature and habitat on individual eel growth chronologies at a small spatial and temporal scale, in order to evaluate the impact of local environmental effects on eel, such as the 2003 summer heat wave. To do this, we modelled individual growth chronologies of eels looking at the influence of habitat and annual temperature on individual yearly growth. For this approach, we used otolith microchemistry proxies for habitat (otolith $\mathrm{Sr} / \mathrm{Ca}$ ) and a thermal proxy in the growth period. The model was fitted on published data (Daverat \& Tomas 2006) of the yellow-phase female European eel in the Gironde River system, France.

\section{MATERIALS AND METHODS}

\section{Dataset and study site}

The present work relies on published data for 171 female European eels Anguilla anguilla collected in the Gironde-Garonne-Dordogne River system, France $\left(45^{\circ} 10^{\prime} \mathrm{N}, 0^{\circ} 45^{\prime} \mathrm{W}\right)$ from 2001 to 2004 by a smallmeshed benthic trawl and fyke nets (see details in Daverat \& Tomas 2006). The overall sample was composed of only $4 \%$ male eels. Therefore, we did not include males in the analyses, to avoid irregularities due to the skewed sex ratio of eels among habitats and insufficient number of males in this system.

The Gironde estuary-the largest in Europa - is $76 \mathrm{~km}$ long and the salinity gradient varies upstream between 33 and 0 psu, changing with tidal cycle and season. Data sets of yellow-phase female Anguilla anguilla were comprised of date of capture, total length $(\mathrm{TL}, \mathrm{mm})$, age $(\mathrm{yr})$, radius of otolith annuli $(\mathrm{mm})$ and $\mathrm{Sr} / \mathrm{Ca}$ ratio (derived from Daverat \& Tomas 2006). Ages-at-capture of female A. anguilla ranged from 2 to $14 \mathrm{yr}(\mathrm{n}=171)$, and significant linear relationships between TL and otolith radius of $A$. anguilla have already been confirmed prior to the analyses. Sr/Ca ratios were analyzed along a transect from the primordium to the postrostrum of otoliths 
using a wave-length dispersive X-ray electron microprobe. Along this transect, the number of otolith annuli was read and the size of each annulus was recorded.

Assessment of the data structure and subsampling were conducted prior to modeling. In order to balance the number of cohorts per year, dataset was subsampled to reduce bias, as it would affect the structure of the data for modeling, if a certain year contained only younger or older eels. We selected years that contained $>30$ data points or not only younger eels (i.e. 1993 to 2003). Only individual growth chronologies containing yellow eels from 1 to $8 \mathrm{yr}$ were selected, as after $8 \mathrm{yr}$ the maturation into silver eel was highly probable in the European silver eel otolith database of the EELREP project (http://cordis.europa.eu/projects/rcn/91640_en.html) It is well known that the silvering of eels is affected by attained body size rather than age (e.g. Vøllestad 1992, Svedäng et al. 1996). Oliveira \& McCleave (2002) noted that faster-growing yellow eels might metamorphose to silver eels and leave the growth habitat at an earlier age than slower-growing eels.

\section{Retrospective growth estimation}

Back-calculation analysis was undertaken using the biological intercept procedure (Campana 1990). It was recognized that there are several potential sources of error for the accuracy of otolith aging experiments and back-calculation methods (experimental limitations and measurement errors on the otolith). The additional problems of data structures might be caused by obtaining a data series from an individual fish. In this study, we had been critical of the accuracy of the method for obtaining estimates of somatic growth in any steps of the estimation (as mentioned in 'Statistical modeling'). Of the otolith radius datasets used in this study, readability of the otolith structures by micrographs were carefully confirmed. The biological intercept method uses a biologically determined intercept in the back-calculation equation using the mean size of the body and the otolith at the elver stage. This is robust to any variations in the fishotolith relationship using the following equation:

$$
L_{i}=L+\left(O_{i}-O\right)\left(L-L_{\text {int }}\right)\left(O-O_{\text {int }}\right)^{-1}
$$

where $L_{i}$ is the back-calculated length of the fish at age $i, O_{i}$ is the size of the otolith at age $i, L$ and $O$ are the size of the fish and otolith, respectively, at capture, and $L_{\text {int }}$ and $O_{\text {int }}$ are the size of the fish and otolith at the biological intercept, respectively. In this study, the mean TL of glass eels when they recruit to coasts $\left(L_{\text {int }}\right)$ was set to $70 \mathrm{~mm}$ (Svedäng et al. 1996). Annual somatic growth at age $i\left(G_{i}: \mathrm{mm}\right)$ was calculated as $G_{i}=L_{i}-L_{i-1}$.

\section{Habitat estimation}

Annual habitat occupied was defined following Fablet et al. (2007), using a proxy of the habitat obtained from $\mathrm{Sr} / \mathrm{Ca}$ measures along a life-history transect. For a detailed description of the method, please refer to Fablet et al. (2007). Originally, in the description by Fablet et al. (2007), 1 habitat is allocated at a temporal scale of $1 \mathrm{mo}$, based on the $\mathrm{Sr} / \mathrm{Ca}$ value acquired along the life-history transect and based on the previous and next values (probability to move or to stay in 1 habitat). The eels in the present study were found to use 3 different habitats: the lower estuary (M), the estuary $(\mathrm{E})$ and the freshwater river (R). For the present study, we retrieved the individual monthly habitatuse chronologies (e.g. RREEEEEEEEEE) from Fablet et al. (2007). We transformed them into individual yearly habitat use: If habitat shift occurred at a certain year, the most dominant habitat was used as the individual yearly habitat (e.g. R, E, or M). The presence/ absence of a habitat shift $(S)$ in a particular year was described as 0 for absence and 1 for presence.

Among calculated classifications of the annual habitat-use patterns of individuals (Fig. 1), residence in 1 habitat of Anguilla anguilla comprised $73 \%$ of the dataset, whereas habitat shifts contributed $27 \%$ to the dataset. According to resident years within 1 habitat, residences of $A$. anguilla in rivers (R: 37\%) and estuaries (E: 45\%) were relatively abundant.

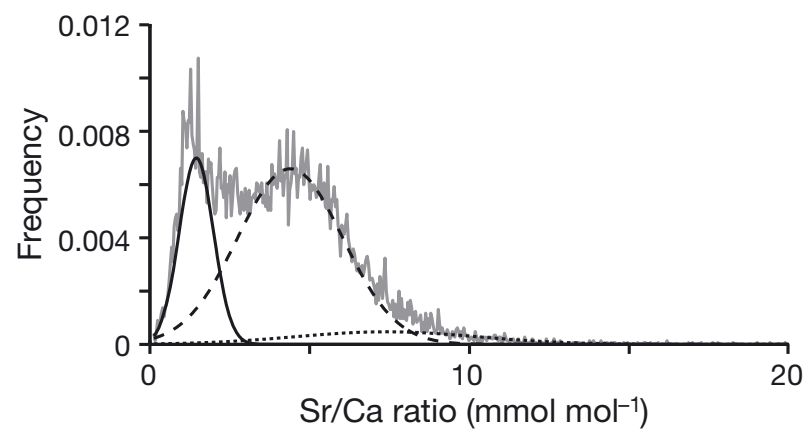

Fig. 1. Anguilla anguilla. Distribution of the Sr/Ca values (grey line) of $A$. anguilla and the modes of the fitted Gaussian model corresponding to different probability distributions. Black solid line: freshwater habitat $(\mathrm{R})$; dashed line: estuarine habitat $(\mathrm{E})$; dotted line: lower estuarine habitat (M) 


\section{Proxy for temperature}

Annual growing degree-days were used in the present study as a proxy for the thermal environment of the river system. Our aim was to represent inter-annual variation of the thermal environment at a whole-river-system scale, so we deployed monthly average air temperatures as reliable and certified values obtained from a local weather station (Fig. 2). In the study system, monthly average air temperature (Mitchell \& Jones 2005) and river water temperature (provided by Centre Nucléaire de Production d'Électricité du Blayais) were significantly correlated during the period from 1999 to $2002\left(\mathrm{r}^{2}=0.95, \mathrm{p}<0.001\right)$. There was an average difference in water temperature of $10 \%$ between the estuary (provided by Électricité de France) and the freshwater sites $100 \mathrm{~km}$ away from the saltwater limit (provided by Association Migrateurs Garonne Dordogne during 1993 and 2003). In the modeling of this study, these differences in temperature between habitats were originally involved in the habitat proxy.

Our thermal proxy $(D)$ was calculated from the sum of the monthly average air temperatures between the lower and higher threshold temperatures as follows:

$$
D_{Y}=\sum_{i=1}^{i=12} F t_{y, i}
$$

where $D_{y}$ is the thermal proxy for temperature at year $y . F t_{y, i}$ is the average forcing temperature in year $y$ and month $i$ calculated as:

$$
\begin{aligned}
& F t_{Y, i}=\left(T_{Y, i}-T_{\text {low }}\right) \text { for } T_{\text {high }}>T_{Y, i}>T_{\text {low }} \\
& F t_{Y, i,}=0 \text { otherwise }
\end{aligned}
$$

where $T_{\text {low }}$ is the lower threshold of temperature and $T_{\text {high }}$ is the higher threshold of temperature.

Eight values of $T_{\text {low }}$ from 9 to $16^{\circ} \mathrm{C}$ and 7 values of $T_{\text {high }}$ from 17 to $23^{\circ} \mathrm{C}$ were tested in the following statistical modeling section.

\section{Statistical modeling}

Individual annual somatic growth of Anguilla anguilla was modeled using a linear mixed-modeling approach to overcome the problem caused by obtaining data series from each individual fish. The functional relationships between the annual somatic growth $(\mathrm{mm})$ as the response variable and the age of individuals (yr), habitat variables and thermal proxy (explanatory variables: fixed effects) were modeled for the eel collection dataset in which multiple values were used from the same fish as a data series (for example, an 8 yr old eel has 8 values in each variable of the model). Thus, the number of observations was given by the number of individuals multiplied by the age of each individual. Individual random effects were included to account explicitly for individual heterogeneity and potential correlation inherent in datasets. Annual somatic growth was natural log transformed to achieve normality. The regression models used here comprised an identity link and normal error distribution, ages nested within the factors (individuals). Therefore, we used the full model with random effects as follows:

$$
G_{j, k}=\alpha+X_{j}+A_{j} \times X_{j}+H_{j, k}+S_{j, k}+D_{j, k}+\varepsilon_{j, k}
$$

where $G_{j, k}$ is the back-calculated annual somatic growth estimate $(\mathrm{mm})$ of individual $j$ at year $k=1-$

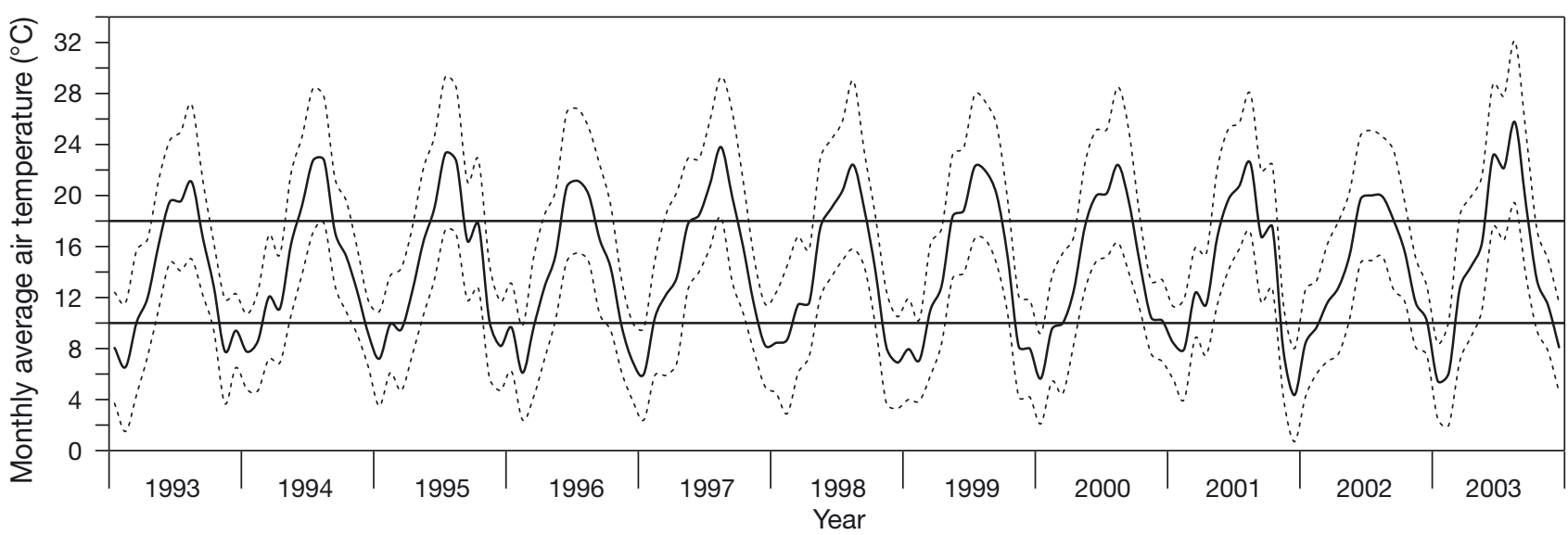

Fig. 2. Temporal dynamics of air temperatures in the Gironde watershed region, France, from 1993 to 2003. Solid line: monthly average temperature; dotted lines: monthly average minimum and maximum temperatures; horizontal lines: selected thermal thresholds for modeling 
$(m-i)$, which is the year in which an eel captured at age $m$ and year $l$ was of age $i(1 \leq i \leq m)$. $\alpha$ is the intercept, $X_{j}$ is the random intercept of individual $j$ with mean zero and common variance, $A_{j} \times X_{j}$ is the age effect $(A)$ with the random slope of individual $j, H_{j, k}$ is the habitat index of individual $j$ at year $k_{,} S_{j, k}$ is the presence/absence of the habitat shift of individual $j$ at year $k, D_{j, k}$ is the thermal proxy calculated as in Eq. (2) for year $k$. The parameter $\varepsilon_{j, k}$ is assumed to be independent errors with mean zero and common variance.

To test random effects structures, the models were assessed with full fixed-effects by considering values of the Akaike information criterion (AIC) and hypothesis tests based on likelihood ratio values (Zuur et al. 2009). A model selection procedure was applied to determine the best model among 56 alternative thermal proxies ( $8 T_{\text {low }} \times 7 T_{\text {high }}$ ) having different ranges of temperature thresholds (e.g. from the proxy with $T_{\text {low }}=9^{\circ} \mathrm{C}, T_{\text {high }}=17^{\circ} \mathrm{C}$ until the proxy with $T_{\text {low }}=$ $16^{\circ} \mathrm{C}, T_{\text {high }}=23^{\circ} \mathrm{C}$ ) assessed by considering values of the AIC. When the difference between the AIC value of a candidate model and the lowest AIC value of the best model $(\triangle \mathrm{AIC})$ was $<2$, the candidate model was not rejected. With determined structure of random effects and range of thermal proxy, significance of the explanatory variables $(A, H, S$ and $D)$ was confirmed by considering values of the AIC and likelihood ratio values. The models were fit to the data using the nlme package in R (Wood 2006).

\section{RESULTS}

The individual growth trajectories of female European eels Anguilla anguilla in relation to the interannual variation of temperature (thermal proxies) and individual habitat-use history from otolith Sr/Ca values were successfully modeled. Individual differences as random intercept and slope had significant effects on the model of the individual growth trajectories for female $A$. anguilla in the Gironde River system (likelihood-ratio test, $\mathrm{p}<0.01$ ). In this study, the model with thermal proxies in the growth periods $>15^{\circ} \mathrm{C}$ and $<18^{\circ} \mathrm{C}$ ranked first among the candidate thresholds considering AIC values (Table 1). Although the model with thermal proxies $>15^{\circ} \mathrm{C}$ in growth periods ranked first among the 8 candidate thresholds of $T_{\text {low }}$, alternative lower threshold models of 12 to $14^{\circ} \mathrm{C}$ tested for $A$. anguilla had small $\Delta$ AICs ranging from 0.8 to 1.0 , indicating that some models were similar to the best model. The selected $T_{\text {low }}$ of 12 to $15^{\circ} \mathrm{C}$ corresponded to the month with a monthly
Table 1. Anguilla anguilla. Comparison of Akaike's information criterion (AIC) for trial candidate models of eel growth using different thresholds of temperature for thermal proxies in the Gironde River system, France. $T_{\text {low }}$ l lower threshold; $T_{\text {high }}$ : higher threshold of the temperature; ns: the tested thermal proxy is not significant in the model. Bold print depicts selected thresholds according to lower AICs

\begin{tabular}{|lccccccc|}
\hline $\begin{array}{c}T_{\text {low }} \\
\left({ }^{\circ} \mathrm{C}\right)\end{array}$ & 17 & 18 & 19 & 20 & 21 & 22 & 23 \\
\hline 9 & $\mathrm{~ns}$ & 679.2 & $\mathrm{~ns}$ & $\mathrm{~ns}$ & $\mathrm{~ns}$ & 681.8 & 685.1 \\
10 & $\mathrm{~ns}$ & 678.8 & $\mathrm{~ns}$ & $\mathrm{~ns}$ & $\mathrm{~ns}$ & 680.8 & 685.2 \\
11 & $\mathrm{~ns}$ & 676.9 & $\mathrm{~ns}$ & $\mathrm{~ns}$ & $\mathrm{~ns}$ & 681.6 & 686.4 \\
12 & 686.8 & $\mathbf{6 7 5 . 5}$ & $\mathrm{ns}$ & $\mathrm{ns}$ & $\mathrm{ns}$ & 681.8 & $\mathrm{~ns}$ \\
13 & 685.3 & $\mathbf{6 7 5 . 6}$ & $\mathrm{ns}$ & $\mathrm{ns}$ & $\mathrm{ns}$ & 682.1 & $\mathrm{~ns}$ \\
14 & 683.9 & $\mathbf{6 7 5 . 2}$ & $\mathrm{ns}$ & $\mathrm{ns}$ & $\mathrm{ns}$ & 682.3 & $\mathrm{~ns}$ \\
15 & 680.0 & $\mathbf{6 7 4 . 4}$ & $\mathrm{ns}$ & $\mathrm{ns}$ & $\mathrm{ns}$ & 682.2 & $\mathrm{~ns}$ \\
16 & 680.6 & 677.1 & $\mathrm{~ns}$ & $\mathrm{~ns}$ & $\mathrm{~ns}$ & $\mathrm{~ns}$ & $\mathrm{~ns}$ \\
& & & & & & & \\
\hline
\end{tabular}

average minimum temperature of about 7 to $11^{\circ} \mathrm{C}$ in a year in the temperature series from 1993 to 2004 of this study (Fig. 2). For higher thresholds of $T_{\text {high }}$, the $18^{\circ} \mathrm{C}$ model was found to be the best model among the 7 candidate thresholds (Table 1), with relatively larger $\triangle \mathrm{AIC}$ values than the others. The $T_{\text {high }}$ of $18^{\circ} \mathrm{C}$ corresponded to the month with a monthly average maximum temperature of about 23 to $24^{\circ} \mathrm{C}$ (Fig. 2). Thermal proxy values $(D)$ for the growth of eels in this river system $\left(T_{\text {low }}=15^{\circ} \mathrm{C}\right.$ and $\left.T_{\text {high }}=18^{\circ} \mathrm{C}\right)$ ranged from 0.2 for 1999 to 6 for 2001 (Table 2). The maximum values of degree-days above $T_{\text {high }}$ and below $T_{\text {low }}$ were 51.4 for 1999 and 38.3 for 1993, respectively (Table 2), in which the average maximum temperature in August 1999 was $27.9^{\circ} \mathrm{C}$ and the average minimum temperature in February 1993 was $1.5^{\circ} \mathrm{C}$ (Fig. 2).

Annual growth modeling for Anguilla anguilla revealed that age, thermal proxy in the growth period (annual thermal variation), habitat category and the presence of a habitat shift had significant effects on model growth (Table 3, Fig. 3). Annual growth of $A$. anguilla was significantly related to annual values of thermal proxies in the growth period. Higher annual growth values were observed in years of larger thermal proxies in the growth periods (Fig. 3).

Predicted annual growth of eels showed higher growth of Anguilla anguilla at a younger age and decreased with age (Fig. 4). Habitat shifts of $A$. anguilla from river to estuary resulted in higher annual growth values compared to annual growth values obtained in freshwater residence, while habitat shifts between estuary and marine habitat had no additional effect on saline residence in the model (Fig. 4). 
Table 2. Anguilla anguilla. Summary of thermal proxies for modeling $A$. anguilla in the Gironde River system, France. Lower and higher thresholds of monthly average temperature were set at 15 and $18^{\circ} \mathrm{C}$, respectively, for $D$ as the inter-annual thermal proxy for the model considering the AIC values of candidate models. Bold: maximum and minimum values for each column

\begin{tabular}{|cccccc|}
\hline Year & $\begin{array}{c}\text { Sum of monthly } \\
\text { average } \\
\text { temperature }\end{array}$ & $\begin{array}{c}\text { Degree-months } \\
\text { beyond thresholds } \\
<15^{\circ} \mathrm{C}\end{array}$ & $\begin{array}{c}\text { Thermal } \\
\text { proxy } \\
\text { pro }\end{array}$ & $\begin{array}{c}\text { Number } \\
(D)\end{array}$ & $\begin{array}{c}\text { of otolith } \\
\text { data }\end{array}$ \\
\hline 1993 & $\mathbf{1 5 9 . 7}$ & $\mathbf{3 8 . 3}$ & $\mathbf{3 0 . 1}$ & 2.9 & 30 \\
1994 & 174.5 & 28.8 & 34.7 & 3.5 & 46 \\
1995 & 173.0 & 32.6 & 35.0 & 5.6 & 67 \\
1996 & 163.0 & 35.8 & 31.9 & 1.9 & 81 \\
1997 & $\mathbf{1 7 8 . 7}$ & 28.2 & 43.1 & 3.8 & 90 \\
1998 & 167.4 & 35.7 & 40.7 & 2.5 & 102 \\
1999 & 171.7 & 34.9 & $\mathbf{5 1 . 4}$ & $\mathbf{0 . 2}$ & 117 \\
2000 & 172.6 & 32.0 & 42.0 & 2.6 & 129 \\
2001 & 166.4 & 37.6 & 33.0 & $\mathbf{6}$ & 110 \\
2002 & 172.8 & $\mathbf{2 5 . 8}$ & 37.7 & 0.9 & 87 \\
2003 & 178.1 & 33.5 & 50.3 & 1.3 & 49 \\
Total & - & - & - & - & 908 \\
\hline
\end{tabular}

Table 3. Anguilla anguilla. Estimates of the fixed effects in the final model for A. anguilla in the Gironde River system, France

\begin{tabular}{|lrlcrrr|}
\hline Variables & $\begin{array}{c}\text { Estimated } \\
\text { coefficient }\end{array}$ & SE & df & $t$ & $\mathrm{p}$ \\
\hline Intercept & 4.140 & 0.039 & 738 & 106.585 & $<0.001$ \\
Age $(A)$ & -0.062 & 0.007 & 738 & -9.167 & $<0.001$ \\
Habitat $(H)$ & -0.073 & 0.031 & 738 & -2.382 & 0.017 \\
Habitat shift $(S)$ & 0.062 & 0.027 & 738 & 2.312 & 0.021 \\
Thermal proxy $(D)$ & 0.023 & 0.006 & 738 & 4.069 & $<0.001$ \\
\hline
\end{tabular}

\section{DISCUSSION}

The results in the present study are in accordance with previous works on eel growth. Estimated growth rates of Anguilla anguilla were found to decrease rapidly with age in the model. A decrease of growth rate with age was also found in previous studies on anguillids (e.g. A. anguilla: Panfili et al. 1994, A. rostrata: Jessop et al. 2004, A. japonica: Yokouchi et al. 2008) and in a population-level model of A. anguilla (Daverat et al. 2012). The model in our study showed that habitat (potentially including thermal differences among habitats) affected the growth of $A$. anguilla in the Gironde River system. Previous studies have reported annual growth rates of yellowphase A. anguilla of between 30 and $60 \mathrm{~mm} \mathrm{yr}^{-1}$ (Moriarty 2003), to almost $100 \mathrm{~mm} \mathrm{yr}^{-1}$ in Mediterranean lagoons (Melia et al. 2006). Within the riversystem scale for other anguillids, growth of yellowphase eel was highly variable within a site of the Hudson River system for A. rostrata (Morrison \& Secor 2003) and the Hamana Lake system for $A$.
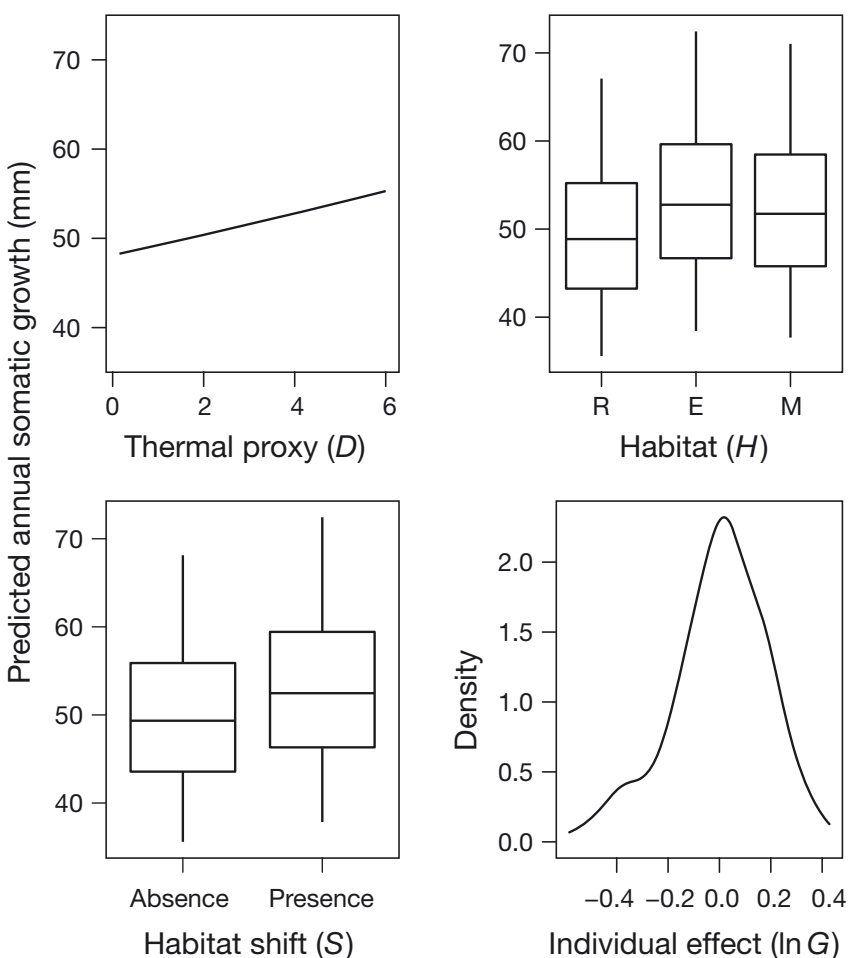

Fig. 3. Anguilla anguilla. Graphic summaries of linear mixedmodel fits for females. The response variable (annual somatic growth) is shown on the $y$-axis and covariates are shown on the $x$-axis: the thermal proxy at the selected higher and lower temperature thresholds of 18 and $15^{\circ} \mathrm{C}$, habitats (R: freshwater river, E: estuary, M: lower estuary) and the presence/absence of habitat shifts. The estimated density of individual effects (random effects) for data on females fits with a mixed-effects model. Box plots depict the upper and lower quartiles, median is represented by a line within each box, range within the outliers is indicated by vertical lines

japonica (Yokouchi et al. 2008). Such a significant effect of habitat on growth was also found in studies using otolith microchemistry for Atlantic eels in which growth rates in brackish water were higher than those in adjacent bodies of freshwater for A. rostrata (e.g. Jessop et al. 2004, 2008, Thibault et al. 2007, Lamson et al. 2009) and for A. anguilla (Daverat $\&$ Tomas 2006). Temperature regime is one of the factors that can explain why growth rates of eels are higher in coastal systems and estuaries. The temperature regime of brackish and marine systems is different from the temperature regime of freshwater habitats. This was verified within the Gironde River basin where there was a $10 \%$ difference in temperatures between the estuary and river. There was a buffer effect in the estuary with less seasonal contrast in temperatures than in freshwater habitats, with higher winter and lower summer temperatures. The lower depth and absence of salt explain why temper- 


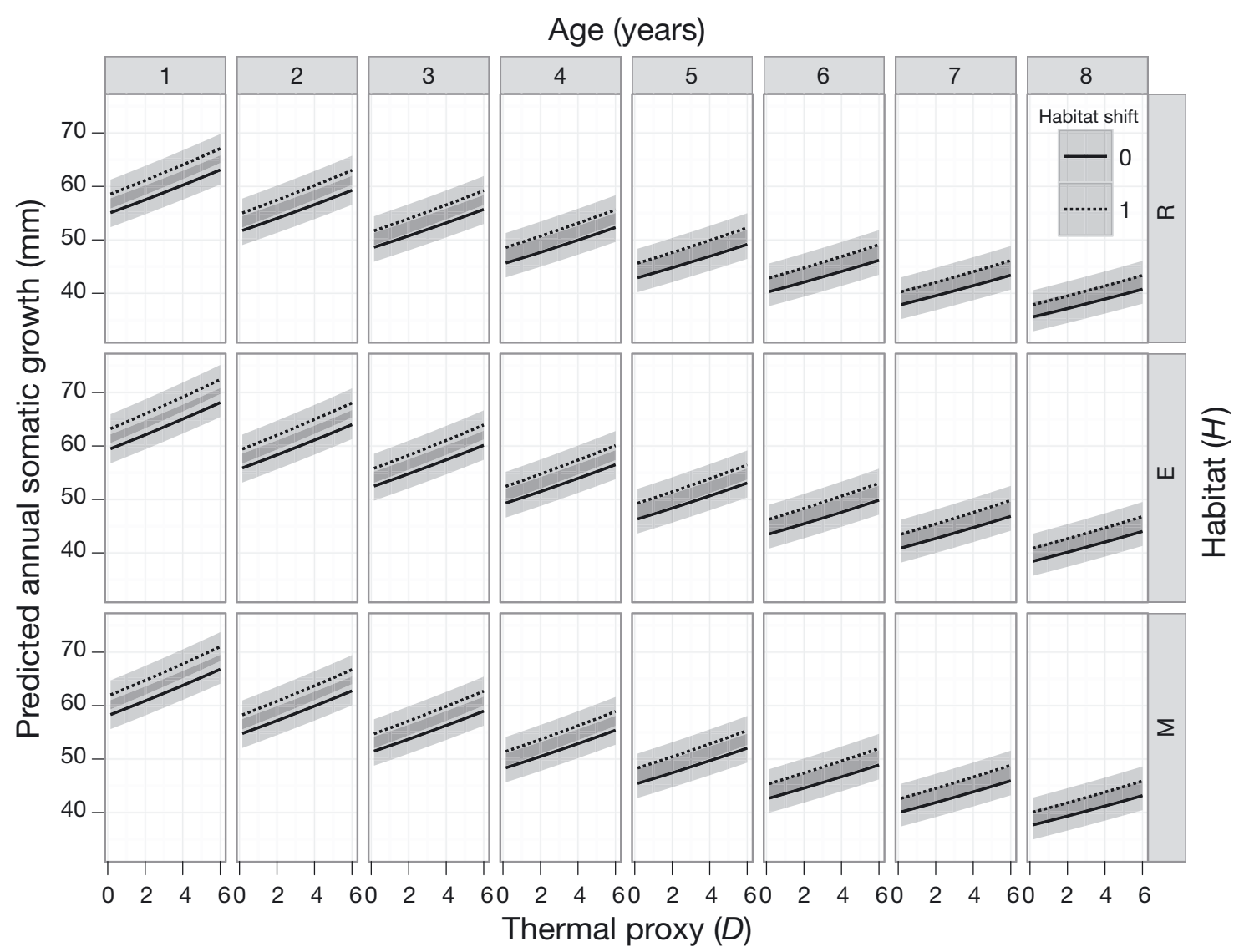

Fig. 4. Anguilla anguilla. Mean annual somatic growth increments of females for each age group in the Gironde River system, as predicted by the mixed-effects model. Shaded areas are $95 \%$ confidence intervals around the fits; overlap of $95 \%$ CI for each category of the habitat shift is depicted by the darker grey. R: freshwater river; E: estuary; M: lower estuary

atures in freshwater habitats vary more closely with air temperature than those in estuaries. Furthermore, in the temperate zone, the productivities of estuaries and coastal ecosystems are higher than those of freshwater habitats (Gross 1987), which has been verified for the Gironde system (Irigoien \& Castel 1997, Lobry et al. 2003).

Thermal proxy in the growth period had a positive effect on individual yearly growth. The thermal proxy was representative of the ecologically optimal temperature conditions for eel growth. The result that the $12^{\circ} \mathrm{C} T_{\text {low }}$ model (selected lowest $T_{\text {low }}$ considering AIC criterion) was consistent with the general observations showing that growth ceased at temperatures $<9^{\circ} \mathrm{C}$ (Moriarty 2003) and in aquaculture conditions at around $13^{\circ} \mathrm{C}$ (Tesch 2003). The selected $T_{\text {high }}$ of $18^{\circ} \mathrm{C}$ was in accordance with a conservative range of optimum temperatures for eel growth. A monthly average air temperature of $18^{\circ} \mathrm{C}$ would be representative of a water temperature of 23 to $24^{\circ} \mathrm{C}$ in the Gironde River system. Previous experimental studies have reported the optimum temperature for eel growth to be around $23^{\circ} \mathrm{C}$ for $A$. anguilla in cap- tivity (Sadler 1979, Panfili et al. 1994). Previous studies indicated that growth decreased rapidly above the optimum temperature for $A$. anguilla in captivity (Sadler 1979).

The years 1999 and 2001 had the lowest and highest thermal proxy values, respectively. A difference in growth between 1999 and 2001 could be explained by a comparatively longer growing season in 2001, due to a warmer winter and moderate summer and a shorter growing season in 1999 due to a hot summer. This suggested that moderate climate conditions for both summer and winter had a positive effect on growth. The heat wave in 2003 had a negative effect on eel growth, as reflected by the second lowest thermal proxy value in the study period. In 2003, the value of degree-days above $T_{\text {high }}$ was also the second highest maximum during the study period, with a value of 50.3, indicating environmental temperatures too high for eel growth. The average maximum temperature in August 2003 reached $32^{\circ} \mathrm{C}$. Under global warming and abnormal climatic events, a gradual shift of growing season from spring/summer to an autumn/winter season could theoretically happen. 
Overall, in theory, eels will benefit from global warming with an extended growing season. However, high summer temperatures would not be the only positive effect on eel growth in the Gironde system. In addition to the direct effect of the highest temperatures on eel growth in this system, the highest thermal environments might lead to negative side effects on eel growth from the related environmental variables. Bevacqua et al. (2011) suggested the possibility that the natural mortality rates of eels increase with temperature. In addition to this, river flow in the Gironde system had a strong negative relationship with temperature in recent decades $\left(\mathrm{r}^{2}=0.37, \mathrm{p}<\right.$ 0.001; data provided by Centre Nucléaire de Production d'Électricité du Blayais). Large temporal variations in river flow were found in this system during the past decade (Schäfer et al. 2002), and the lowest river flow during the hottest summer can be explained by climate-related agricultural water use in this region. It seems convincing that the higher temperatures associated with low amounts of river discharge could potentially produce adverse effects, such as lower oxygen concentrations and higher contaminant concentrations. However, further investigations of the negative side effects of higher temperatures on eel growth are needed.

The model linking yearly temperature variability, the individual trajectories of habitat used and the annual growth of eels could be applicable in other systems to estimate the growth pattern of Anguilla anguilla. The large-scale latitudinal difference observed for eel growth (Vøllestad 1992, Jessop 2010, Daverat et al. 2012) supports the hypothesis of a strong relation between temperature and growth dynamics. The individual-scale model in this study for the growth trajectory of European eel could be used to assess the precise growth in the specific habitat category and thermal environment of a certain year in order to conduct effective eel management. The application of this modeling framework, using the datasets from several locations, could in future contribute to finding the optimum spatio-temporal zone with respect to eel growth under the constraints of environmental changes due to anthropogenic impacts and changing climate.

Acknowledgements. The authors are grateful to Géraldine Lassalle and Christine Delpech for their assistance in collecting environmental data, and to Patrick Lambert, Eric Rochard, Russell Poole and Gregory N. Nishihara for their valued suggestions. We sincerely thank 3 anonymous referees and the responsible editor, who all provided comments that improved the manuscript. The study was funded by the CPER programs of Region Aquitaine, France.

\section{LITERATURE CITED}

Aoyama J (2009) Life history and evolution of migration in catadromous eels (genus Anguilla). Aqua-BioSci Monogr $2: 1-42$

Bevacqua D, Melià P, De Leo GA, Gatto M (2011) Intraspecific scaling of natural mortality in fish: the paradigmatic case of the European eel. Oecologia 165:333-339

> Black BA (2009) Climate-driven synchrony across tree, bivalve, and rockfish growth-increment chronologies of the northeast Pacific. Mar Ecol Prog Ser 378:37-46

> Cairns DK, Secor DA, Morrison WE, Hallett JA (2009) Salinity-linked growth in anguillid eels and the paradox of temperate-zone catadromy. J Fish Biol 74:2094-2114

> Campana SE (1990) How reliable are growth backcalculations based on otoliths? Can J Fish Aquat Sci 47:2219-2227

Ciccotti E, Fontenelle G (2001) A review of eel Anguilla anguilla aquaculture in Europe: perspectives for its sustainability. J Taiwan Fish Res 9:27-43

Daverat F, Tomas J (2006) Tactics and demographic attributes in the European eel Anguilla anguilla in the Gironde watershed, SW France. Mar Ecol Prog Ser 307: $247-257$

> Daverat F, Beaulaton L, Poole R, Lambert P and others (2012) One century of eel growth: changes and implications. Ecol Freshwat Fish 21:325-336

> Dosoretz C, Degani G (1987) Effect of fat rich diet and temperature on growth and body composition of European eels (Anguilla anguilla). Comp Biochem Physiol A 87: 733-736

> Fablet R, Daverat F, De Pontual H (2007) Unsupervised Bayesian reconstruction of individual life histories from otolith signatures: case study of Sr:Ca transects of European eel (Anguilla anguilla) otoliths. Can J Fish Aquat Sci 64:152-165

Francis R (1990) Back-calculation of fish length: a critical review. J Fish Biol 36:883-902

Gross MR (1987) Evolution of diadromy in fishes. In: Dadswell MJ, Klauda RJ, Moffitt CM, Saunders RL, Rulifson RA, Cooper JA (eds) Common strategies of anadromous and catadromous fishes. American Fisheries Society Symposium 1, American Fisheries Society, Bethesda, MD, p 12-25

Helfman GS, Facey DE, Stanton Hales Jr L, Bozeman EL (1987) Reproductive ecology of the American eel. In: Dadswell MJ, Klauda RJ, Moffitt CM, Saunders RL, Rulifson RA, Cooper JA (eds) Common strategies of anadromous and catadromous fishes. American Fisheries Society Symposium 1, American Fisheries Society, Bethesda, MD, p 42-56

Holmgren K (1996) Effect of water temperature and growth variation on the sex ratio of experimentally reared eels. Ecol Freshwat Fish 5:203-212

IPCC (Intergovernmental Panel on Climate Change) (2001) Climate change 2001: the scientific basis. Contribution of Working Group I to the 3rd assessment report of the IPCC. Cambridge University Press, Cambridge

Irigoien X, Castel J (1997) Light limitation and distribution of chlorophyll pigments in a highly turbid estuary: the Gironde (SW France). Estuar Coast Shelf Sci 44:507-517

> Jessop BM (2010) Geographic effects on American eel (Anguilla rostrata) life history characteristics and strategies. Can J Fish Aquat Sci 67:326-346

> Jessop BM, Shiao JC, Iizuka Y, Tzeng WN (2004) Variation 
in the annual growth, by sex and migration history, of silver American eels Anguilla rostrata. Mar Ecol Prog Ser 272:231-244

> Jessop BM, Cairns DK, Thibault I, Tzeng WN (2008) Life history of American eel Anguilla rostrata: new insights from otolith microchemistry. Aquat Biol 1:205-216

Jolly WM, Dobbertin M, Zimmermann NE, Reichstein M (2005) Divergent vegetation growth responses to the 2003 heat wave in the Swiss Alps. Geophys Res Lett 32:L18409, doi:10.1029/2005GL023252

Kaifu K, Tamura M, Aoyama J, Tsukamoto K (2010) Dispersal of yellow phase Japanese eels Anguilla japonica after recruitment in the Kojima Bay-Asahi River system, Japan. Environ Biol Fishes 88:273-282

Lamson HM, Cairns DK, Shiao JC, Iizuka Y, Tzeng WN (2009) American eel, Anguilla rostrata, growth in fresh and salt water: implications for conservation and aquaculture. Fish Manag Ecol 16:306-314

Lobry J, Mourand L, Rochard E, Elie P (2003) Structure of the Gironde estuarine fish assemblages: a comparison of European estuaries perspective. Aquat Living Resour 16: 47-58

Melia P, Bevacqua D, Crivelli AJ, De Leo GA, Panfili J, Gatto M (2006) Age and growth of Anguilla anguilla in the Camargue lagoons. J Fish Biol 68:876-890

Mitchell TD, Jones PD (2005) An improved method of constructing a database of monthly climate observations and associated high-resolution grids. Int J Climatol 25: 693-712

Moriarty C (2003) The yellow eel. In: Aida K, Tsukamoto K, Yamauchi K (eds) Eel biology. Springer-Verlag, Tokyo, p 89-105

Morrison WE, Secor DH (2003) Demographic attributes of yellow-phase American eels (Anguilla rostara) in the Hudson River estuary. Can J Fish Aquat Sci 60: 1487-1501

Oliveira K, McCleave JD (2002) Sexually different growth histories of the American eel in four rivers in Maine. Trans Am Fish Soc 131:203-211

Panfili J, Ximenes MC, Crivelli AJ (1994) Sources of variation in growth of the European eel (Anguilla anguilla) estimated from otoliths. Can J Fish Aquat Sci 51:506-515

Sadler K (1979) Effects of temperature on the growth and

Editorial responsibility: Asbjørn Vøllestad, Oslo, Norway survival of the European eel, Anguilla anguilla L. J Fish Biol 15:499-507

Schäfer J, Blanc G, Lapaquellerie Y, Maillet N, Maneux E, Etcheber H (2002) Ten-year observation of the Gironde tributary fluvial system: fluxes of suspended matter, particulate organic carbon and cadmium. Mar Chem 79: 229-242

Svedäng H, Neuman E, Wickström H (1996) Maturation patterns in female European eel: age and size at the silver eel stage. J Fish Biol 48:342-351

Tesch FW (2003) The eel. Blackwell, Oxford

- Thibault I, Dodson JJ, Caron F, Tzeng WN, Iizuka Y, Shiao JC (2007) Facultative catadromy in American eels: testing the conditional strategy hypothesis. Mar Ecol Prog Ser 344:219-229

Tsukamoto K, Arai T (2001) Facultative catadromy of the eel Anguilla japonica between freshwater and seawater habitats. Mar Ecol Prog Ser 220:265-276

Tsukamoto K, Nakai I, Tesch WV (1998) Do all freshwater eels migrate? Nature 396:635-636

Tzeng WN, Lin HR, Wang CH, Xu SN (2000) Differences in size and growth rates of male and female migration Japanese eel in Pearl River, China. J Fish Biol 57: 1245-1253

> Vøllestad LA (1992) Geographic-variation in age and length at metamorphosis of maturing European eel: environmental effects and phenotypic plasticity. J Anim Ecol 61: $41-48$

Weisberg S, Spangler G, Richmond LS (2010) Mixed effects models for fish growth. Can J Fish Aquat Sci 67:269-277

Wood SN (2006) Generalized additive models. An introduction with R. Chapman \& Hall/CRC, Boca Raton, FL

> Yokouchi K, Aoyama J, Oka HP, Tsukamoto K (2008) Variation in the demographic characteristics of yellow-phase Japanese eels in different habitats of the Hamana Lake system, Japan. Ecol Freshwat Fish 17:639-652

Yokouchi K, Fukuda N, Miller MJ, Aoyama J, Daverat F, Tsukamoto K (2012) Influences of early habitat use on the migratory plasticity and demography of Japanese eels in central Japan. Estuar Coast Shelf Sci 107:132-140

Zuur AF, Ieno EN, Walker NJ, Saveliev AA, Smith GM (2009) Mixed effects models and extensions in ecology with R. Springer, New York, NY

Submitted: November 20, 2012; Accepted: July 15, 2013

Proofs received from author(s): September 19, 2013 